\title{
Lanthionine Synthetase C-Like 2 Modulates Immune Responses to Influenza Virus Infection
}

\begin{abstract}
Andrew Leber, Josep Bassaganya-Riera, Nuria Tubau-Juni, Victoria Zoccoli-Rodriguez, Pinyi Lu, Victoria Godfrey, Shiv Kale and Raquel Hontecillas*
\end{abstract}

Nutritional Immunology and Molecular Medicine Laboratory, Biocomplexity Institute, Virginia Tech, Blacksburg, VA, USA

Broad-based, host-targeted therapeutics have the potential to ameliorate viral infections without inducing antiviral resistance. We identified lanthionine synthetase C-like 2 (LANCL2) as a new therapeutic target for immunoinflammatory diseases. To examine the therapeutic efficacy of oral NSC61610 administration on influenza, we infected C57BL/6 mice with influenza A H1N1pdm virus and evaluated influenza-related mortality, lung inflammatory profiles, and pulmonary histopathology. Oral treatment with NSC61610 ameliorates influenza virus infection by down-modulating pulmonary inflammation through the downregulation of $\mathrm{TNF}-\alpha$ and $\mathrm{MCP}-1$ and reduction in the infiltration of neutrophils. NSC61610 treatment increases IL10-producing CD8+ T cells and macrophages in the lungs during the resolution phase of disease. The loss of LANCL2 or neutralization of IL-10 in mice infected with influenza virus abrogates the ability of NSC61610 to accelerate recovery and induce IL-10-mediated regulatory responses. These studies validate that oral treatment with NSC61610 ameliorates morbidity and mortality and accelerates recovery during influenza virus infection through a mechanism mediated by activation of LANCL2 and subsequent induction of IL-10 responses by CD8+ T cells and macrophages in the lungs.

Keywords: influenza virus, immunoregulation, LANCL2, IL-10, drug discovery, infection resolution

\section{INTRODUCTION}

Seasonal influenza causes an estimated 200,000 hospitalizations and 25,000-35,000 deaths annually in the United States, afflicting mainly people older than 65 years of age (1). Aside from the seasonal $\mathrm{flu}$, pandemic influenza originating from emerging strains can significantly change the disease dynamics. Influenza pandemics cause considerable disease, with associated mortality ranging from approximately 50 million deaths during the 1918 pandemic to 1 to 4 million deaths in 1957 and approximately 1 million deaths in 1968. In 2009, a novel H1N1 virus emerged and spread rapidly in humans, causing severe disease in susceptible populations and high numbers of respiratory- and cardiovascular-related deaths (2). Overall, seasonal flu is one of the most relevant infectious diseaserelated public health problems since it causes important economic losses ranging from 71 to 166 billion dollars during one influenza pandemic (3).

Current approaches for the prevention and treatment of influenza infections include vaccination and early administration of antiviral drugs (4). Typically, a minimum of 6 months are needed to develop a new vaccine, creating a lag period between the identification of a new strain and the administration of the first vaccine doses, in which the population is unprotected against the virus (5). The use of antiviral drugs is associated with the emergence of resistance. A promising therapeutic avenue 
is the modulation of the host response to the virus by targeting the immune system in the pulmonary mucosa and systemically to minimize viral pneumonia and improve survival rates (6). The excessive release of pro-inflammatory cytokines in the lungs often leads to a cytokine storm, which is a key contributor to lung immunopathology and disease severity. For example, mortality induced by the highly pathogenic $\mathrm{H} 5 \mathrm{~N} 1$ strain correlates with high levels of circulating cytokines and chemokines (7). Hence, the use of drugs that target the host response instead of directly targeting the virus or its cytopathic effects is receiving attention for the treatment of infections $(8,9)$. In contrast to vaccines, immune modulators and inflammation blockers provide efficacy independently of changes in viral antigenicity, are fast acting, and are relatively inexpensive (10), although they have not been approved as host-targeted therapeutics. Moreover, in contrast to antivirals, immune modulators do not cause resistance.

We have recently investigated the potential role of abscisic acid (ABA), as a ligand of lanthionine synthetase C-like 2 (LANCL2) leading to elevation of intracellular cAMP and activation of protein kinase A (PKA) (11). We used molecular modeling approaches to predict the binding of ABA to LANCL2 (12). In vitro studies have confirmed direct binding of ABA to LANCL2 (13). Moreover, oral administration of ABA as a pre- and postexposure therapeutic upregulates LANCL2 expression in the lungs of influenza-infected mice, reduces influenza virus-related immunopathology, and accelerates recovery in infected mice (14). LANCL2 is widely expressed in specialized organs of the immune system, including blood, spleen, lymph node, and thymus. LANCL2 is expressed by T cells, macrophages, endothelial and epithelial cells, and dendritic cells suggesting its potential as a target for immunoregulation (15). Other members of the LANCL family of proteins include LANCL2 which has been shown to contribute to cellular homeostasis and nervous system disorders $(16,17)$.

In this study, we examined the feasibility of using LANCL2 ligands to induce immunoregulatory responses and ameliorate morbidity and mortality associated with influenza virus infection. PubChem compound 247228, a 3,3'-bis(benzimidazolyl) terephthalanilide (BTT), also known as NSC61610 was selected from the National Cancer Institute Diversity Set II by LANCL2 structure-based virtual screening and previously shown to induce immunomodulatory effects in mouse models of colitis $(18,19)$. Additionally, the safety and efficacy profiles of BT-11, a newly developed LANCL2 ligand, are excellent based on single and 14 -day repeated-dose toxicology studies in rats and in four mouse models of inflammatory bowel disease (IBD) (20-23). Given the demonstrated efficacy of $\mathrm{ABA}$ in accelerating recovery in mouse models of influenza virus infection (14), in this study, we investigated the effects of NSC61610 in a mouse model of infection, elucidating its underlying immunoregulatory mechanisms, LANCL2 dependency, and cell specificity in the lungs.

\section{MATERIALS AND METHODS}

\section{Animal Procedures}

Eight- to ten-week-old wild-type C57BL/6 mice and LANCL2 knockout mice on a C57BL/6 background were challenged intranasally with $350 \mathrm{pfu} /$ mouse of Influenza A H1N1pdm strain. NSC61610-treated mice within this study received $20 \mathrm{mg} / \mathrm{kg} /$ day of NSC61610 orally by gavage. Formulations of NSC61610 treatment were prepared in PBS containing $25 \mathrm{mg}$ 2-hydroxypropyl-beta-cyclodextrin (HPBCD) per mg NSC61610. Untreated mice received equal volume of sterile PBS containing HPBCD. NSC61610 was given from day 0 to day 12, daily in 24-hour intervals. Mice treated with oseltamivir phosphate were given $10 \mathrm{mg} /$ $\mathrm{kg}$ /day in two doses separated by $12 \mathrm{~h}$. All mice were weighed daily. Mice were housed at the animal facilities at Virginia Tech. Mice ( $n=10-15$ per group and time point) were sacrificed at 3 , 7 , or 12 days post-infection (dpi), and samples were collected for analysis of gene expression, immunophenotyping of infiltrating cells, and histopathological examination. IL-10 neutralization was conducted by intraperitoneal injection of anti-IL10 antibody (R\&D Systems \#MAB417); $100 \mu \mathrm{g} /$ mouse was injected on the same day as NSC61610 treatment initiation. The initial dosage was followed with a $50-\mu \mathrm{g} /$ mouse dose on days 6 and 9 post-infection.

All experimental procedures were approved by the Institutional Animal Care and Use Committee (IACUC) of Virginia Tech and met or exceeded requirements of the Public Health Service/ National Institutes of Health and the Animal Welfare Act. The IACUC approval IDs for the study were 10-157-VBI and 14-007VBI. Mice were monitored every $4 \mathrm{~h}$ post-infection and humanely euthanized.

\section{Histopathology}

Lung samples were collected at 3, 7, or 12 days post-infection and fixed in $10 \%$ buffered formalin. Samples were stained with hematoxylin and eosin and lesions were graded 0-4 on the following categories: (1) epithelial necrosis, (2) perivascular cuffing, (3) leukocytic infiltration of the mucosa and submucosa of large airways, and (4) terminal airway infiltration. Tissue slides were examined in an Olympus microscope (Olympus America Inc., Dulles, VA, USA).

\section{Quantitative Real-time RT-PCR}

Total RNA was isolated from lungs. Quantitative PCR was performed on the cDNA using Taq DNA polymerase (Invitrogen, Carlsbad, CA, USA) and using previously described conditions (24). Purified amplicons were used to optimize quantitative realtime RT-PCR conditions and to generate standard curves. Primer concentrations and annealing temperatures were optimized for the iCycler iQ system (Bio-Rad) for each set of primers using the system's gradient protocol. cDNA concentrations for genes of interest were examined by RT-PCR using an iCycler IQ System and the iQ SYBR green supermix (Bio-Rad) (24). A standard curve was generated for each gene using 10-fold dilutions of purified amplicons starting at $5 \mathrm{pg}$ of cDNA. In order to determine the number of products synthesized during the real-time PCR, a melting curve analysis was performed on each product. RT-PCR was used to measure the starting amount of nucleic acid of each unknown sample of cDNA on the same 96-well plate. Results are presented as starting quantity of target cDNA (picograms) per microgram of total RNA as previously described (24). 


\section{Immunophenotyping of Immune Cells Infiltrating the Lungs of Mice}

The whole left lobe was collected in $15 \mathrm{~mL}$ of $1 \times$ RPMI supplemented with FBS, HEPES, and calcium chloride and chopped into small pieces to facilitate the digestion. Lung digestion was performed by adding $300 \mathrm{U} / \mathrm{mL}$ of Collagenase and $50 \mathrm{U} / \mathrm{mL}$ of DNAse and incubated for $60-90 \mathrm{~min}$ at $37^{\circ} \mathrm{C}$ under agitation. Cell yield was measured in a particle counter (Beckman Coulter) after digestion and subsequent filtration through $100 \mu \mathrm{m}$ strainers. Red blood cells were eliminated by hypotonic lysis, and cells were finally resuspended in $1 \mathrm{~mL}$ of PBS containing 5\% serum and $0.09 \%$ sodium azide (FACS buffer). Cells were incubated with combinations of up to 9 antibodies to markers [CD3 (clone: 1452C11), CD4 (clone: GK1.5), CD8 (clone: 53-6.7), CD11b (clone: M1/70), CD11c (clone: HL3), CD19 (clone: MB19-1), CD45 (clone: 30-F11), F4/80 (clone: BM8), Gr1 (clone: 1A8), Ly6C (clone: HK1.4), MHC-II (clone: M5/114.15.2), NK1.1 (clone: PK136), SiglecF (clone: E50-2440), CX3CR1 (clone: AHP566), CD64 (clone: X54-5/7.1), PD-1 (clone: J43), and IL-10 (clone: JES5-16E3)]. Antibodies were purchased from eBioscience with the exception of CD11b, CD64, and SiglecF (Becton Dickinson) and CX3CR1 (BioRad). Thirty thousand events were computed in a LSRII flow cytometer (Becton Dickinson). Hematopoietic cell phenotype analysis was performed in FACS diva with the following gating discrimination: (1) live cells based of FS versus SS, (2) doublet exclusion based on FSC versus FSW, and (3) selection of CD45+ events.

\section{Plaque Assay}

MDCK cells were grown to confluency within six-well plates. Cells were washed of serum containing media prior to exposure. Serial dilutions of virus sample were made in serum-free growth media containing fraction V BSA. Cells were incubated with $1 \mathrm{~mL}$ of virus dilution for $1 \mathrm{~h}$ at $37^{\circ} \mathrm{C}$. Supernatant was removed and cells were washed. Cells were overlayed with a MEM agar mixture and incubated for $72 \mathrm{~h}$. Overlay was removed, and wells were stained with crystal violet. Lowest dilution with at least 50 plaques was counted.

\section{Expression and Purification of the Recombinant LANCL2 Proteins}

Transformed BL21(DE3) E. coli cells were initially cultured in Luria-Bertani medium with $100 \mu \mathrm{g} / \mathrm{mL}$ ampicillin at $37^{\circ} \mathrm{C} 240 \mathrm{RPM}$ until the culture reached an $\mathrm{A}_{600}$ of 0.3. GSTLANCL2 was expressed by adding $0.1 \mathrm{mM}$ isopropyl- $\beta-\mathrm{D}-$ thiogalactopyranoside. Induced cells were incubated for $16 \mathrm{~h}$ at $20^{\circ} \mathrm{C} 170 \mathrm{RPM}$. Cells were harvested by centrifugation $45 \mathrm{~min}$ $1,559 \mathrm{RCF}$ and lysed by sonication in $50 \mathrm{mM}$ Tris- $\mathrm{HCl}, \mathrm{pH} 8.0$, $150 \mathrm{mM} \mathrm{NaCl}$ with $0.3 \mathrm{mM}$ Tris(2-carboxyethyl)phosphine (TCEP). Post membrane disruption, lysates were centrifuged at $17,211 \mathrm{RPM}$ for $20 \mathrm{~min}$ at $4^{\circ} \mathrm{C}$. GST-LANCL2 fusion protein was purified by affinity chromatography using Glutathione (GSH)-Sepharose-4B (GE Healthcare). GST-LANCL2 was eluted from GSH-Sepharose-4B by incubating the resin with $10 \mathrm{mM}$ GSH in $50 \mathrm{mM}$ Tris- $\mathrm{HCl}$, pH 8.0, $150 \mathrm{mM} \mathrm{NaCl}$ with $0.3 \mathrm{mM}$ TCEP. GST-LANCL2 proteins were run through a gel filtration column. The fusion proteins were further purified by the AKTA Fast protein liquid chromatography purification systems (GE Healthcare). Protein concentrations were determined by bicinchoninic acid assay. Protein purity was assessed by SDS-PAGE; gels were stained with ProSieve Blue Protein Staining solution.

\section{Sensor Chip Preparation}

Direct binding experiments were performed via the Biacore T200 surface plasmon resonance (SPR) Technology (Georgetown University). The flow rates were $10 \mu \mathrm{L} / \mathrm{min}$ for all capture and initial testing studies and $100 \mu \mathrm{L} / \mathrm{min}$ for affinity studies. The GST-LANCL2 was immobilized to a CM4 chip by amine coupling method. Two adjacent surfaces were activated by injection of a 1:1 (v:v) mixture of $0.1 \mathrm{M} N$-hydroxysuccinimide (NHS) and $0.4 \mathrm{M}$ 1-ethyl-3-(3-dimethyl-aminopropyl)-carbodiimide hydrochloride (EDC) for 720 s. Experimental flow cell was then injected with the GST-LANCL2 that was diluted in $10 \mathrm{mM} \mathrm{pH}$ 5.5 sodium acetate buffer to a final concentration of $25 \mu \mathrm{g} / \mathrm{mL}$. Both experimental and the reference flow cells were inactivated by injection of $1 \mathrm{M}$ Ethanolamine- $\mathrm{HCl} \mathrm{pH} 8.0$ for $720 \mathrm{~s}$.

\section{Kinetic Studies of ABA and NSC61610}

A final GST-LANCL2 surface density $\left(\mathrm{R}_{\mathrm{L}}\right)$ of 7,500 RU equivalent to an $\mathrm{R}_{\max }$ of 53 and $26 \mathrm{RU}$ for NSC61610 and ABA, respectively, was obtained. Following initial binding studies, it was determined that binding of small molecules to the LANCL2 was occurring with a fast off rate. Therefore, no regeneration step was required following small molecule injections. Binding affinity was calculated following injection of small molecules at four different concentrations $(12.5,6.25,3.13$, and $1.57 \mu \mathrm{M})$ in triplicates. Injection time was $60 \mathrm{~s}$ and dissociation time was $300 \mathrm{~s}$. Running buffer for binding studies was $25 \mathrm{mM}$ MOPS (pH 6.5), $150 \mathrm{mM} \mathrm{NaCl}, 0.05 \%$ P-20, 5\% DMSO. Data were analyzed by using the BiaEvaluation software v1 (GE Healthcare) with 1:1 binding model for steady state affinity. Raw data were exported and graphed using Prizm for Mac v5.0d.

\section{Statistical Analysis}

Data from the first mouse challenge study were analyzed as a series of factorial arrangement designs. To determine the statistical significance of the model, we performed analysis of variance (ANOVA) using the general linear model procedure of Statistical Analysis Software, and $p$-value $<0.05$ was considered to be significant. When the model was significant, ANOVA was followed by Fisher's protected least significant difference multiple comparison method.

\section{RESULTS}

\section{LANCL2 Aids in Resolution and Recovery from Influenza Infection}

To assess the role of LANCL2 in the response to influenza infection, wild-type C57BL6/J mice and LANCL2-/- mice were infected with $350 \mathrm{pfu} /$ mouse of influenza A H1N1/California/04/09. Notably, LANCL2-/- mice had a decreased rate of survival and prolonged presence of symptoms (Figures 1A,B). Within 
the lungs of infected mice, LANCL2-/- possessed lower levels of IL-10 and higher levels of IL- 6 at day 12 post-infection (Figures 1I,J). In general, LANCL2-/- displayed lower numbers of IL-10-producing cells within the lungs during the same period and specifically within CX3CR1+ macrophage and CD8+ T cell populations (Figures 1C-E). LANCL2-/- mice also showed lesser numbers of tissue repair and homeostasis cell types in alveolar macrophages and type 2 innate lymphoid cells at day 12 post-infection(Figures 1G,H) while displaying greater number of neutrophils at day 7 post-infection (Figure 1F).

\section{Myeloid LANCL2 Is Required for Modulation of Regulatory Responses}

Using a cre-recombinase system, myeloid (LANCL2fl/fl;LysCre+) and $\mathrm{T}$ cell-(LANCL2fl/fl;CD4Cre+) specific knockouts of LANCL2 were generated. Myeloid cell knockouts recapitulated the LANCL2-/- phenotype in terms of mortality (Figure 2A). Both cell specific knockouts displayed decreased levels of IL-10 within the lungs at day 12 post-infection similar to the LANCL2-/(Figure 2B). In addition, IL-10-producing macrophages and CD8+ $\mathrm{T}$ cells were similarly decreased in CD4Cre+ and
LysCre+ compared to LANCL2-/- (Figures 2D,E). However, LANCL2fl/fl;CD4Cre+ mice had significantly increased numbers of alveolar macrophages compared to LANCL2-/- and LANCL2fl/fl;LysCre+ mice (Figure 2F). The number of alveolar macrophages in LANCL2fl/fl;CD4Cre+ was similar to numbers in untreated wild-type mice. LANCL2fl/fl;CD4Cre+ mice also displayed lower concentrations of MCP-1 in lung homogenate than LANCL2-/- and LANCL2fl/fl;LysCre+ mice (Figure 2C). Together, these data suggest that a myeloid-specific LANCL2 deficiency is capable of producing the same effects as the full body deletion of the protein.

\section{Oral NSC61610 Treatment Improves Influenza Virus-Associated Lung Immunopathology and Protects Mice against Lethal Influenza Virus Infection}

After observation of the importance of LANCL2 in the resolution phase of infection, we sought to identify if novel ligands of LANCL2 could aid in the response to influenza. First, to validate in silico predictions that NSC61610 would bind to LANCL2, LANCL2 was expressed in E. coli. The binding of NSC61610
A

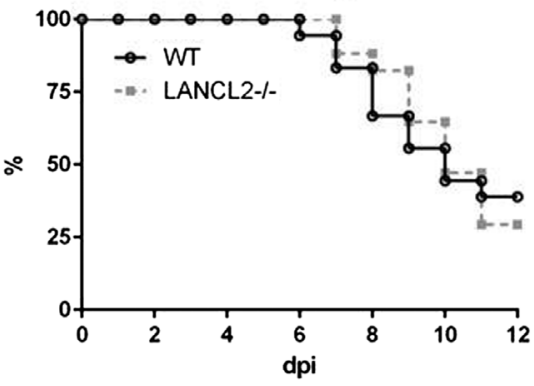

C

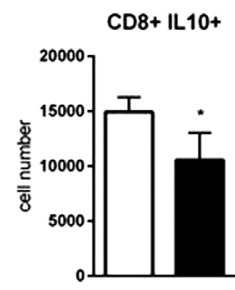

G

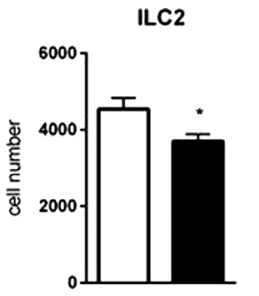

D cxsc

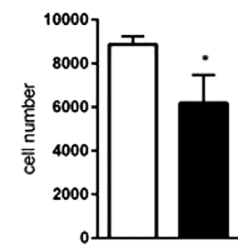

H

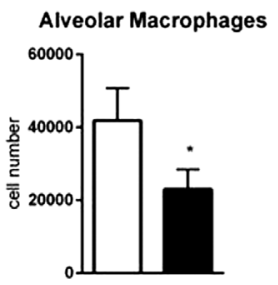

\section{B}

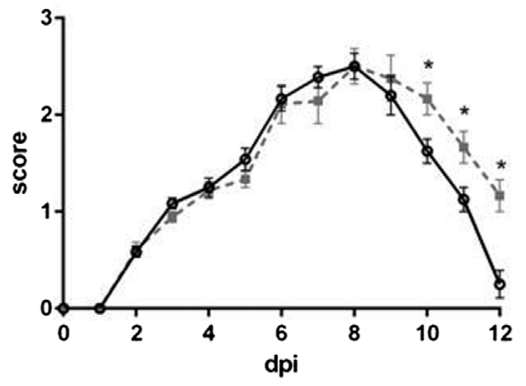

\#. LANCL2-I-

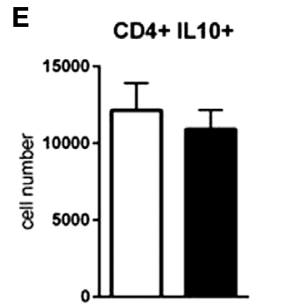

I

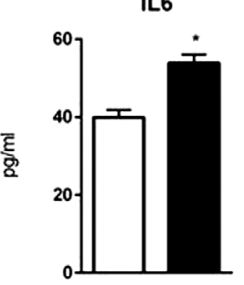

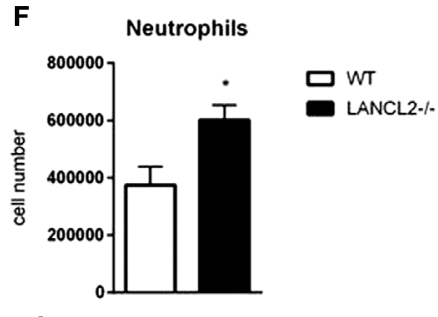

$\mathbf{J}$

IL10

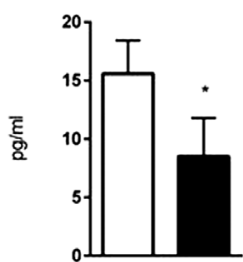

FIGURE 1 Loss of LANCL2 impairs resolution of influenza virus infection. Mortality (A) and disease activity (B) of WT and LANCL2-/- mice infected with influenza. Cell number of CD8+ IL10+ T cells (C), IL10-producing macrophages (D), CD4+ IL10+T cells (E), neutrophils (F), type 2 innate lymphoid cells (G), and alveolar macrophages $\mathbf{( H )}$ at day 12 post-infection by flow cytometry. Concentration of IL-6 (I) and IL-10 (J) in lung homogenate at day 12 post-infection by cytokine bead array. Data points and error bars represent mean \pm standard error of the mean (SEM). Asterisks ${ }^{*}$ ) denote statistically significant $(p<0.05)$ differences between the treatment group and control $(n=12)$. 
A
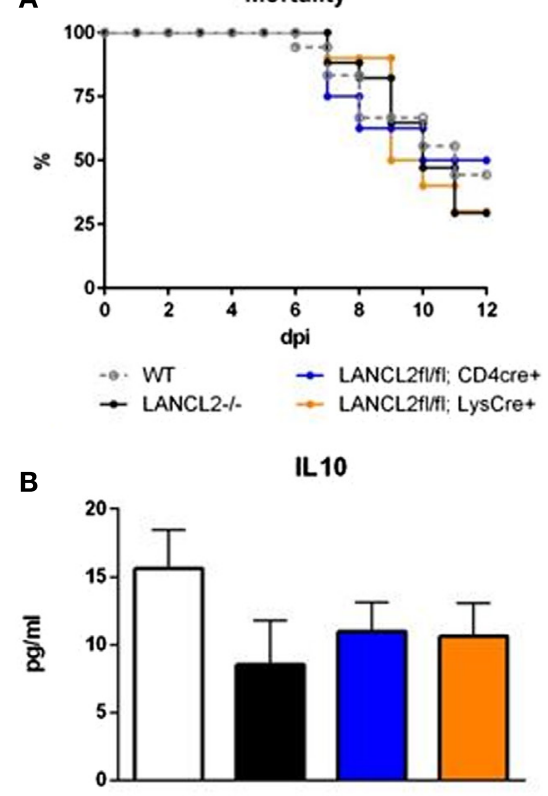

C

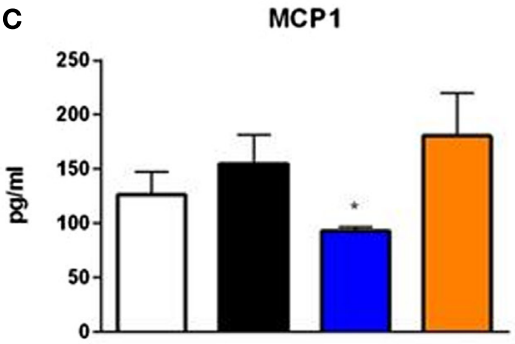

D

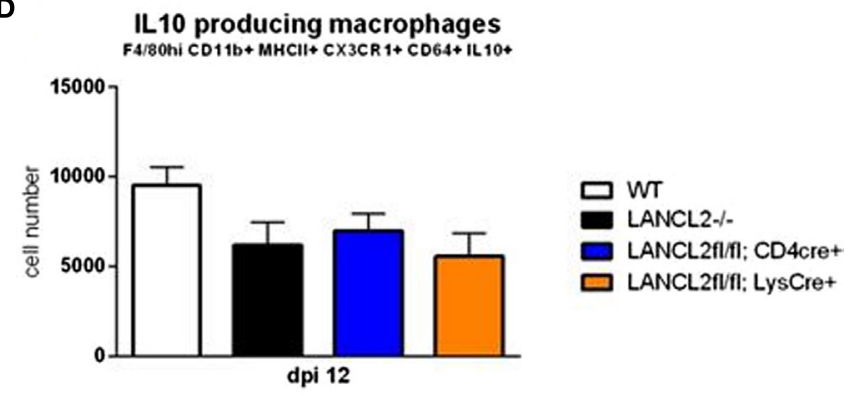

CD8+ IL10+

E $\mathrm{CO} 8+\mathrm{CD} 3+\mathrm{CO} 4-\mathrm{NK1} 1-1-\mathrm{LL} 10+$
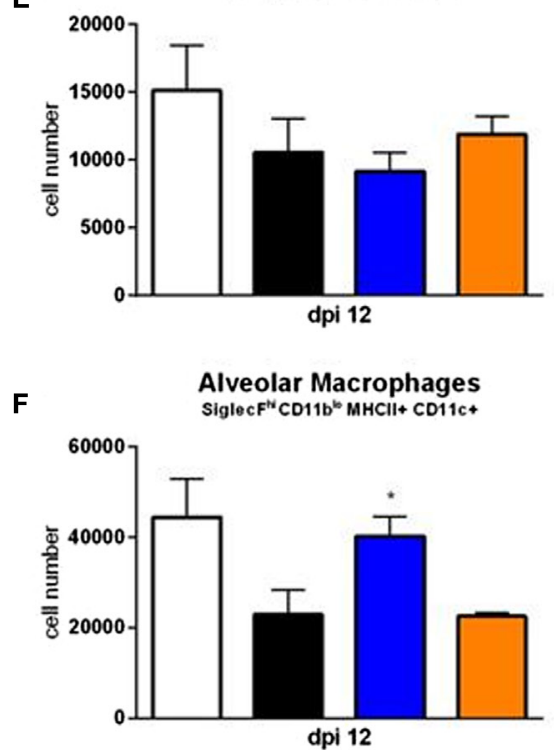

口WT

LANCL2flff: CD4cre+ $\square$ LANCL2flffi; LysCre+

FIGURE 2 | Myeloid LANCL2 is required for modulation of regulatory responses. Mortality (A) for LANCL2-/-, LANCL2fl/fl;CD4Cre+, and LANCL2fl/ fl;LysCre+ mice infected with influenza H1N1. Concentration of IL-10 (B) and MCP1 (C) within lung homogenate by cytokine bead array. Cell number of CX3CR1+ IL-10+ macrophages (D), CD8+ IL-10+ T cells (E), and alveolar macrophages (F) in lungs by flow cytometry at 12 days post-infection. Data points and error bars represent mean \pm SEM. Asterisks $\left({ }^{*}\right)$ denote statistically significant $(p<0.05)$ differences between genotypes $(n=8)$.

to the purified protein was analyzed via SPR and compared to the natural ligand of LANCL2, ABA (Figure 3). Steady state equilibrium constants $\left(K_{\mathrm{D}}\right)$ were determined to be $2.252 \mu \mathrm{M}$ for the ABA-LANCL2 interaction, while the NSC61610-LANCL2 was $2.305 \mu \mathrm{M}$. Following the validation of binding, we performed an assessment of the ability of NSC61610 to improve influenza virus-induced morbidity and/or mortality. C57BL/6 wild-type mice were challenged with $350 \mathrm{pfu} /$ mouse of influenza A H1N1/ California/04/09. At 12 days post-infection, the mortality rate was $60 \%$ in the control group versus 30\% in the NSC61610-treated mice (Figure 4I). The onset of mortality differed by 1 day with the untreated wild-type group beginning on day 6 compared to day 7 in the NSC61610-treated groups. Mice were also scored on a daily basis through observation of physical activity and appearance. NSC61610-treated mice were significantly more active and showed less signs of distress by this measure (Figure 4J). Our clinical data show that oral NSC61610 treatment improves the resolution of infection and accelerates the recovery from disease. These findings are in line with the lower mortality rates recorded in the group that received oral NSC61610 treatment.

To determine whether the improved clinical symptoms observed in NSC61610-treated mice were accompanied by decreased lung pathology, we evaluated microscopic lung lesions at 3, 7, and 12 days post-infection. Examination of lung tissue was based on epithelial necrosis, including presence of debris in large and intermediate size airways, and leukocytic infiltration of the mucosa and submucosa of large airways. Chronologically, the first pulmonary lesion detected was epithelial cell necrosis, with presence of necrotic cells in the airway compartment at day 7 (Figures 4B,E) and marginated leukocytes in adjacent blood vessels and in some cases with perivascular edema. At later stages, the predominant findings were leukocytic infiltration of the mucosa and submucosa of large and medium size airways (Figures $\mathbf{4 A}, \mathbf{B}, \mathbf{D}, \mathbf{E}$ ). This was followed by the presence 
A

Binding of abscisic acid to LANCL2

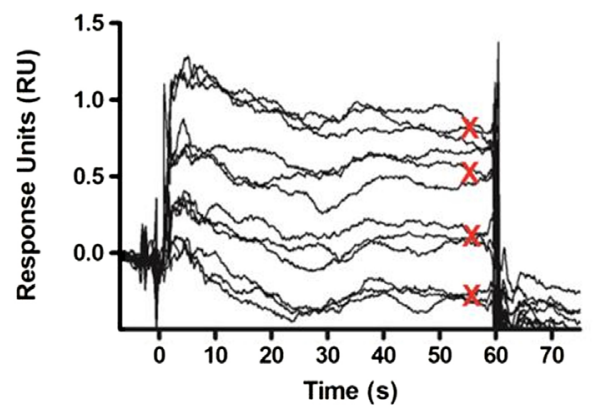

B Binding of abscisic acid to LANCL2

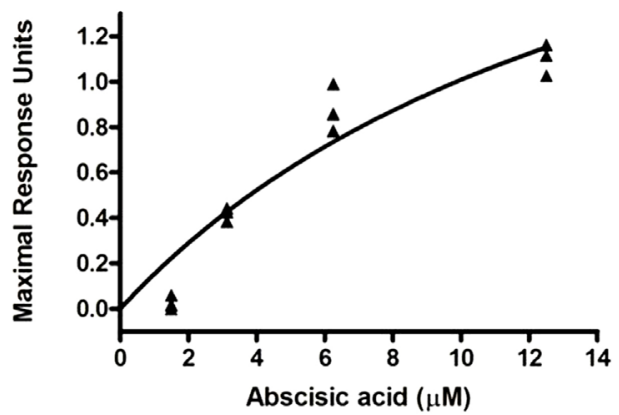

C

Binding of NSC61610 to LANCL2

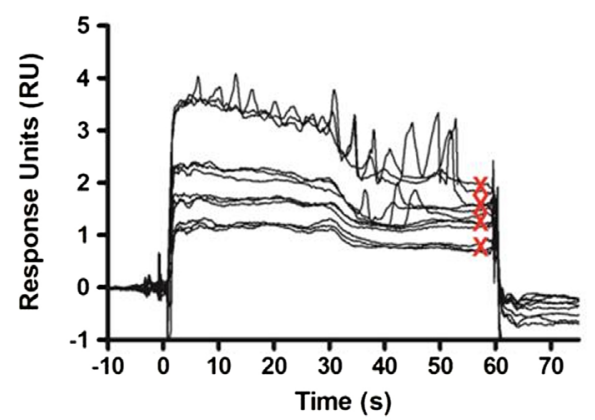

D Binding of NSC61610 to LANCL2

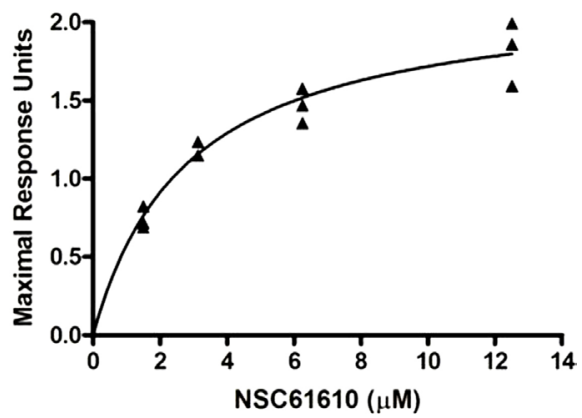

FIGURE 3 | Binding kinetics of lanthionine synthetase C-like 2 (LANCL2) with abscisic acid (ABA) and NSC61610. Surface plasmon resonance (SPR) sensorgrams for the binding of varying concentrations of ABA (12.5, 6.25, 3.13, and $1.57 \mu \mathrm{M})$ to immobilized LANCL2 (A). Plot of maximal resonance unit versus concentration of ABA (B). Steady-state dissociation constant was calculated to be $2.252 \mu \mathrm{M}$ utilizing a 1:1 binding model. SPR sensograms for the binding of varying concentrations of NSC61610 (12.5, 6.25, 3.13, and $1.57 \mu \mathrm{M})$ to immobilized LANCL2 (C). Plot of maximal resonance unit versus concentration of NSC61610 (D). Steady state dissociation constant was calculated to be $2.305 \mu \mathrm{M}$ utilizing a 1:1 binding model.

of inflammatory cells in the terminal airways (Figures $4 \mathrm{C}, \mathbf{F}$ ) on day 7 post-infection. To determine whether NSC61610 ameliorated lung immune-pathology associated with infection, we scored these lesions from 0 to 4 depending on extent and severity. The analysis shows that NSC61610 indeed exerted a significant impact in the extent of lung epithelial necrosis (Figure 4G) and leukocytic infiltration (Figure 4H). The decline in epithelial necrosis scores occurred 2 days earlier in NSC61610-treated mice when compared to untreated mice. Additionally, the severity of leukocytic infiltration was significantly lower in NSC61610-treated mice on day 7 post-challenge than in untreated mice. In untreated mice, the immune cell infiltration increased to reach a maximum score of 3 on day 7 . In the NSC61610-treated mice the score was maintained under 2 throughout the experiment, suggesting lower inflammatory cells recruited to the lungs.

In NSC61610-treated wild-type mice, oral treatment of NSC61610 increases expression of LANCL2 throughout the time course of influenza infection (Figure $4 \mathbf{K}$ ). To confirm the decrease in inflammatory cell types during the peak of infection in NSC61610-treated mice, we measured the mRNA expression of inflammatory markers, IFN $\alpha, \mathrm{TNF} \alpha$ and MCP1, in the lungs of infected mice (Figures 4L-N). Notably, NSC61610 treatment reduced expression of TNF $\alpha$, at day 7 post-infection, and MCP1 at days 3 and 7 post-infection. IFN $\alpha$ was not significantly altered at any of the observed time points.

\section{NSC61610 Promotes Immunological Mechanisms of Regulation and Repair in the Lungs}

Oral administration of NSC61610 increases the number of IL-10-producing macrophages and CD8+ T cells (Figures 5A,B). The numbers of IL-10-producing CD4+ $\mathrm{T}$ cells and induced $\mathrm{T}$ regulatory cells were not changed by treatment (Figures 5G,H). Numbers of polymorphonuclear myeloid-derived suppressor cells, alveolar macrophages and innate lymphoid cell type 2 were also significantly increased at day 12 post-infection (Figures 5C-E). Meanwhile, neutrophils were slightly suppressed at the peak, day 7, of infection (Figure 5F). Using a cytokine bead array, the concentration in lung homogenate of cytokines was measured at day 12 post-infection. The concentration of IL-10 was significantly increased by oral NSC61610 treatment (Figure 5I). Trends in IL-10 production were further confirmed by qRT-PCR with lung tissue (Figure 5M). No significant trends were observed in IL-6, MCP1 or IFN $\gamma$ at day 12 post-infection (Figures 5J-L). Expression of amphiregulin was also observed to be significantly increased by oral NSC61610 treatment (Figure 5N). 

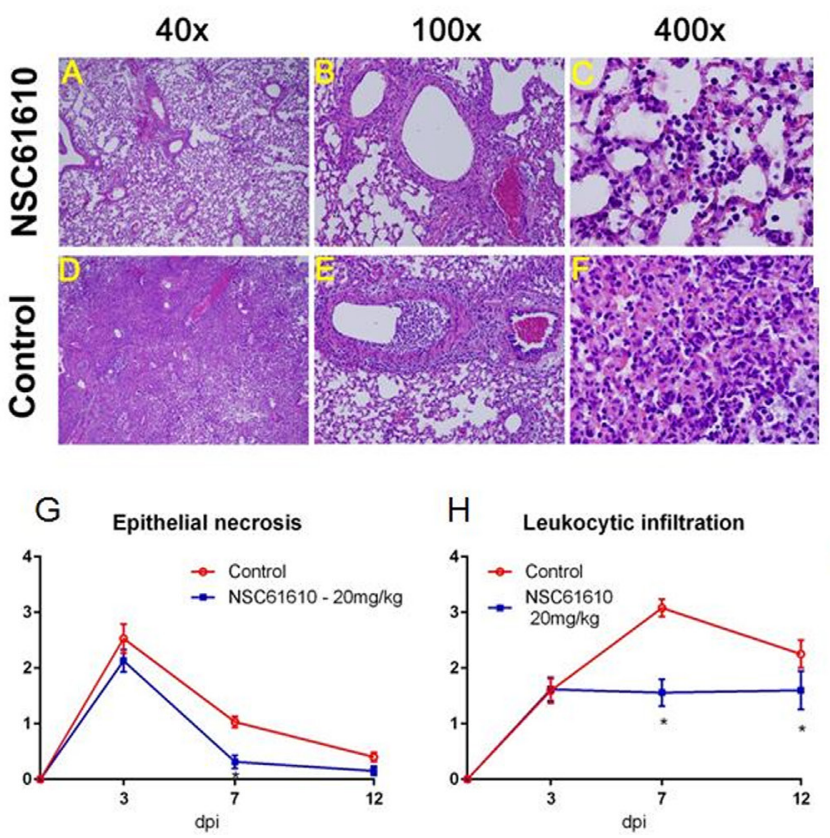

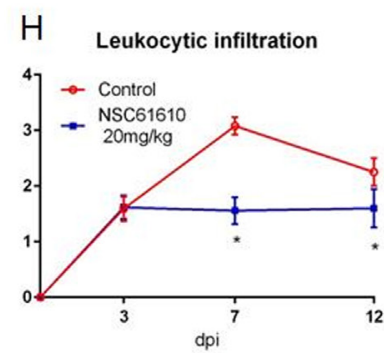

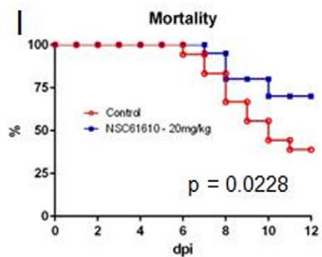
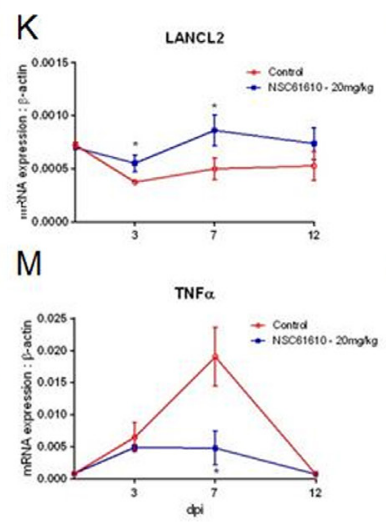
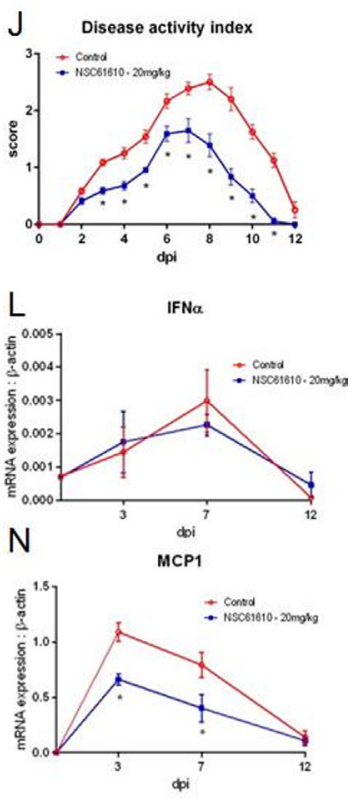

FIGURE 4 | NSC61610 treatment decreases severity and improves recovery from influenza virus infection. Representative photomicrographs of H\&E stained lung sections from NSC61610 (A-C) and control treated (D-F) mice following influenza infection. Summary of epithelial necrosis (G) and leukocytic infiltration (H) scores. Mortality (I) and disease activity $\mathbf{( J )}$ of WT mice infected with influenza with no treatment and NSC61610 treatment. mRNA expression of LANCL2 (K), IFN $\alpha$ (L), TNF $\alpha(\mathbf{M})$, and MCP1 (N) at days 0, 3, 7, and 12 post-infection in lung tissue during influenza infection of wild-type mice administered PBS or NSC61610 (20 mg/kg) by qRT-PCR. Data points and error bars represent mean \pm SEM. Asterisks $\left(^{\star}\right)$ denote statistically significant $(p<0.05)$ differences between the treatment group and control $(n=12)$.

\section{LANCL2 Is Required for the Beneficial Effects of NSC61610}

As NSC61610 is a predicted ligand of LANCL2, we sought to evaluate the specificity of the ligand's effects in LANCL2-/mice. To determine if the efficacy of NSC61610 treatment is dependent on the presence of LANCL2, we administered PBS or NSC61610 to infected LANCL2-/- mice. No significant differences were apparent in mortality or disease activity scores (Figures 6A,B). Additionally, no differences were observable in cellular (Figures 6C-F) or molecular (Figures 6G-J) measures noted to be changed in wild-type mice treated with NSC61610.

\section{Effects of NSC61610 Are Mediated by IL-10}

Mice were infected with influenza virus as previously. After infection, mice were administered an IL-10 neutralizing antibody or isotype control. IL-10-neutralized mice treated with NSC61610 exhibited no differences from untreated IL-10-neutralized mice in clinical measures of disease activity index and mortality (Figures 7A,B). The isotype control antibody did not dampen the efficacy of NSC61610 against influenza. The IL-10 neutralization inhibited the increases in alveolar macrophages, CD103+ dendritic cells, and ILC2 experienced with NSC61610 treatment (Figures 7C,D,G). The neutralization of IL-10 also significantly increased the number of IFN $\gamma$-producing CD4+ $\mathrm{T}$ cells (Figure 7F). However, the neutralization of IL-10 did not reduce the NSC61610-mediated increase in myeloid-derived suppressor cells (Figure 7E).

\section{NSC61610 or Combined Therapy with NSC61610 and Tamiflu Outperforms \\ Tamiflu Alone}

To determine whether the treatment efficacy of NSC61610 could be further increased by combination with an antiviral agent, we administered NSC61610 in combination with oseltamivir phosphate, an active ingredient of Tamiflu. NSC61610 and combination treatment improved the overall mortality and disease activity compared with treatment with oseltamivir alone (Figures 8A,B). Notably, treatment only with Tamiflu did not promote cellular regulatory responses within the lungs while the combination therapy retained the regulatory benefits of NSC61610 treatment (Figures 8C-E). After the observation that treatment with NSC61610 induces regulatory and anti-inflammatory effects, we sought to determine if these effects impacted the viral burden within the lungs. The amount of virus was titrated by plaque assay of MDCK cells. Treatment with NSC61610 did not alter the amount of virus detected. Both Tamiflu and combination therapies significantly reduced the viral titer (Figure 8F).

\section{DISCUSSION}

The LANCL2 pathway has emerged as a therapeutic target for inflammatory, chronic, and immune-mediated diseases (15). 


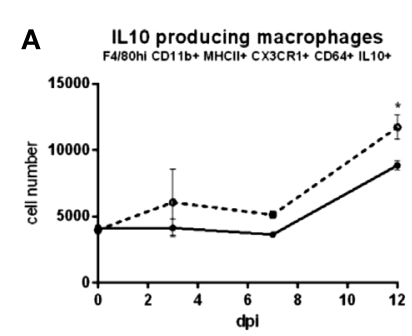

D

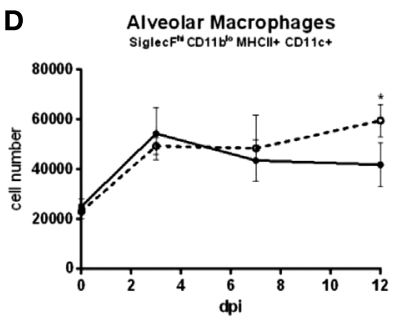

B

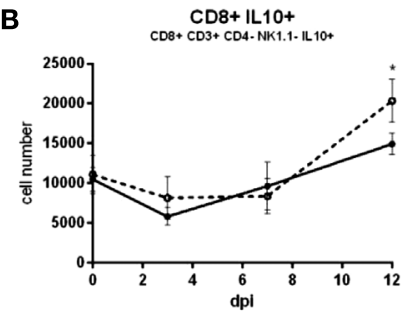

E

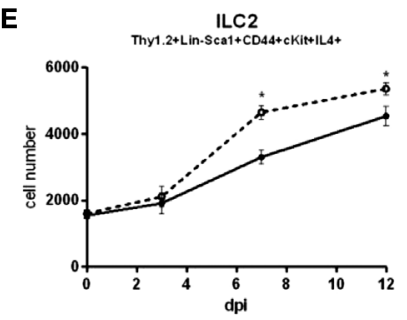

C

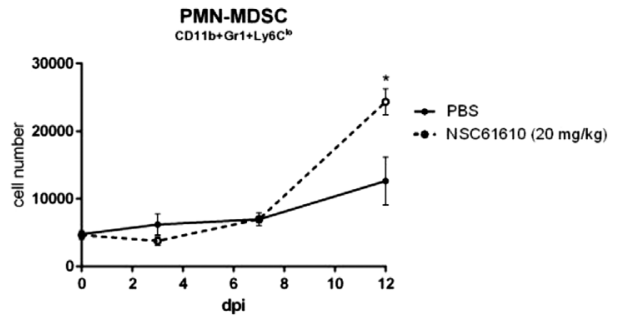

F

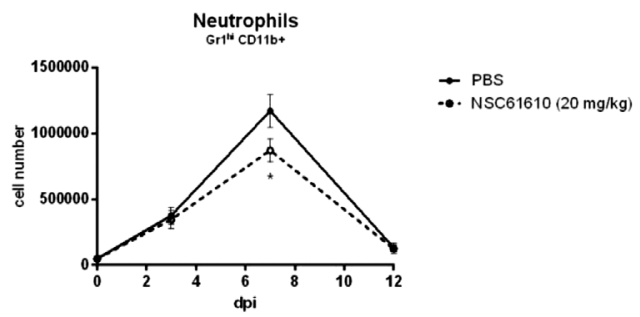

G

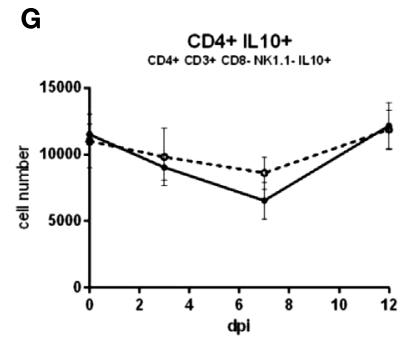

K

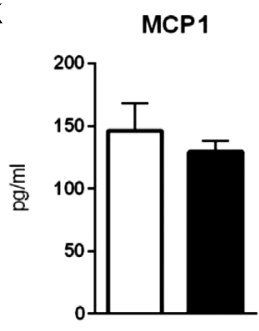

H
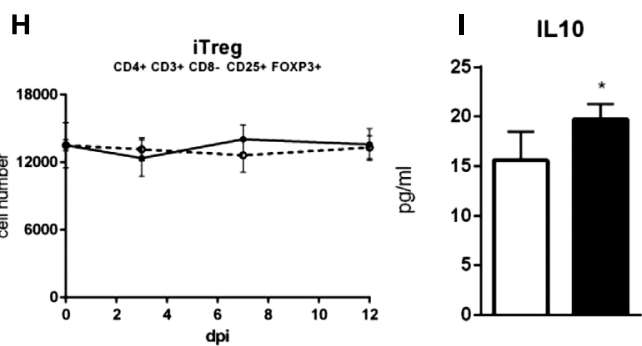

J
IL6

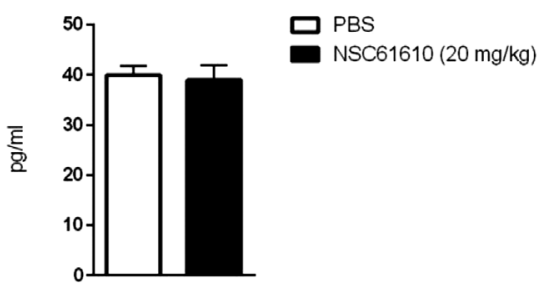

L IFNy

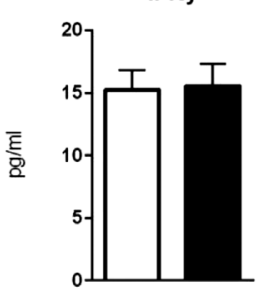

$\mathbf{M}$

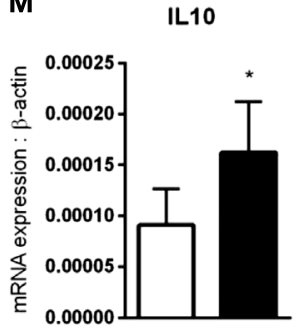

$\mathbf{N}$

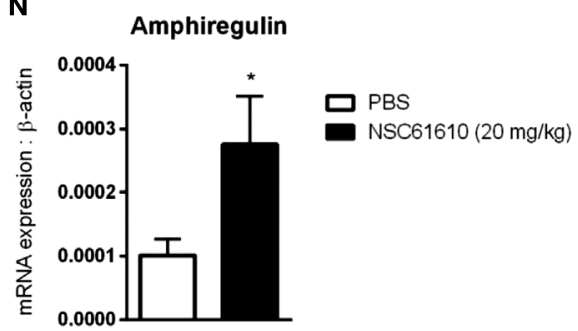

FIGURE 5 | NSC61610 Promotes Regulatory Responses during Resolution Phase of Infection. Cell number of IL10-producing macrophages (A), CD8+ IL10+ T cells (B), polymorphonuclear myeloid-derived suppressor cells (C), alveolar macrophages (D), type 2 innate lymphoid cells (E), neutrophils (F), CD4+ IL10+ T cells (G), and induced T regulatory cells $\mathbf{( H )}$ through day 12 post-infection by flow cytometry. Concentration of IL-10 (I), IL-6 (J), MCP-1 (K), and IFN $\gamma(\mathbf{L})$ in lung homogenate at day 12 post-infection by cytokine bead array. mRNA expression of IL10 (M) and amphiregulin (N) in lung at day 12 post-infection by qRT-PCR. Data points and error bars represent mean \pm standard error of the mean $(\mathrm{SEM})$. Asterisks $\left(^{*}\right)$ denote statistically significant $(p<0.05)$ differences between the treatment group and control $(n=12)$.

By using pharmacologic activation of LANCL2 and loss-offunction approaches in knockout mice, we validate the LANCL2 pathway as a putative target for the treatment of influenza infection. ABA binds to LANCL2 (13) and causes elevation of intracellular CAMP and activation of PKA in macrophages (11). In addition, ABA suppressed LPS-induced inflammation in mice (11), experimental colitis $(25,26)$, and accelerated recovery in influenza virus-driven lung immunopathology (14). Previous work on ABA illustrates the similarities in host defense mechanisms between plants and animals and the importance of understanding a common evolutionary heritage. Based on the demonstrated efficacy of $\mathrm{ABA}$ as an immune modulatory compound and the discovery of the anti-inflammatory efficacy of the LANCL2 pathway, we screened chemical databases to identify new compounds that bind to LANCL2 and found that NSC61610 had the highest predicted binding affinity (19). Previous studies demonstrated the efficacy of NSC61610 as an anti-inflammatory compound in mouse models of colitis (19). Moreover, BT-11, a new LANCL2 ligands being developed for treating IBD, has an outstanding safety profile based on single and 14-day repeated-dose toxicology studies in rats, and it outperforms current IBD treatments in mice with dextran sodium sulfate colitis (20-22). Recently, the binding of LANCL2 to ligand has been shown to affect the cellular localization of 
A

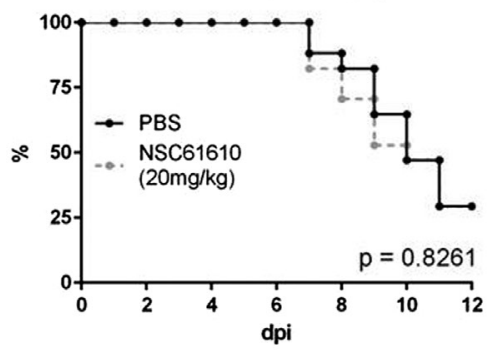

B LANCL2-/-Disease activity index

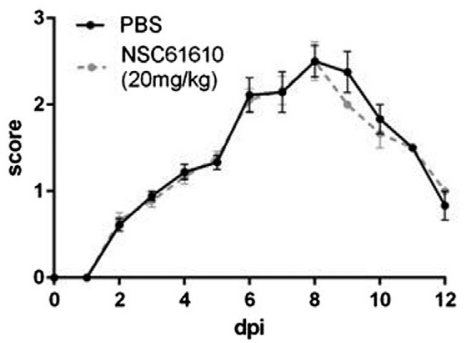

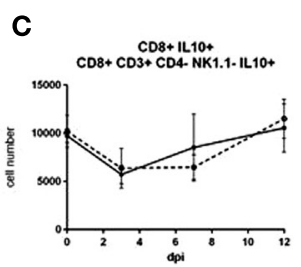

D
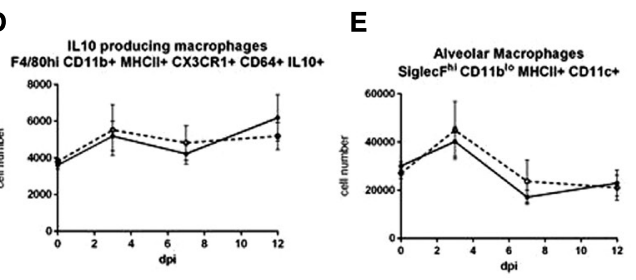

$\mathbf{F}$

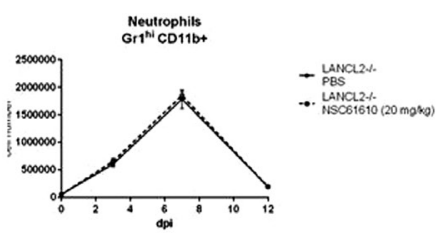

G

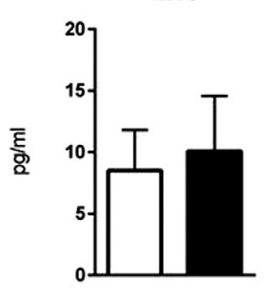

H

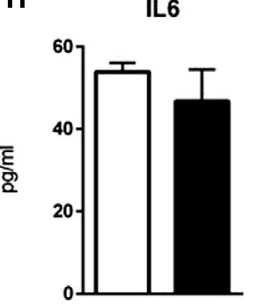

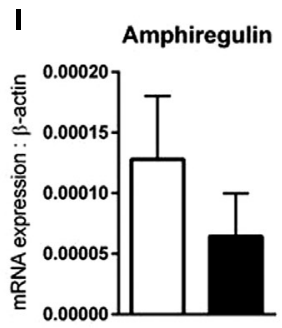

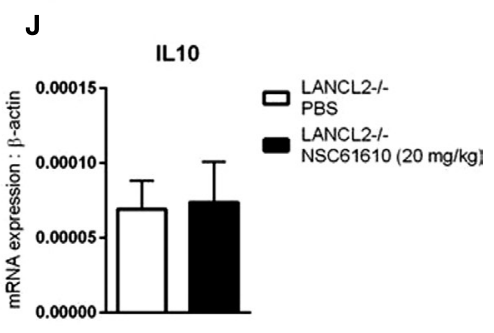

FIGURE 6 | Loss of LANCL2 impairs recovery and diminishes clinical effects of NSC61610 treatment. Mortality (A) and disease activity (B) of LANCL2-/mice infected with influenza with no treatment and NSC61610 treatment. Cell number of CD8+ LL10+ T cells (C), IL10-producing macrophages (D), alveolar macrophages $\mathbf{( E )}$, and neutrophils $\mathbf{( F )}$ through day 12 post-infection by flow cytometry. Concentration of IL-10 (G) and IL-6 (H) in lung homogenate at day 12 post-infection by cytokine bead array. mRNA expression of amphiregulin (I) and IL10 (J) in lung at day 12 post-infection by qRT-PCR. Data points and error bars represent mean \pm SEM. Asterisks $\left(^{*}\right)$ denote statistically significant $(p<0.05)$ differences between the treatment group and control $(n=12)$.

LANCL2 resulting in multiple methods of promoting downstream effects (27).

Our in vivo results demonstrate for the first time that oral treatment with NSC61610 and activation of the LANCL2 pathway ameliorates pulmonary immunopathology during influenza A virus infection by suppressing inflammation and enhancing IL-10mediated immunoregulatory responses in the lungs. Specifically, oral treatment with NSC61610 lowered infiltration of the airway mucosa and submucosa and decreased epithelial necrosis in lungs of infected mice. NSC61610 exerted its anti-inflammatory effect by suppressing TNF- $\alpha$ and MCP-1 expression during early and peak phases. TNF- $\alpha$ is a pro-inflammatory cytokine implicated in priming epithelial cells for induced cytokine and chemokine production during influenza A virus infection, while MCP1 contributes to the recruitment of immune cells (28). Anti-TNF- $\alpha$ humanized antibodies, such as Remicade (Centocor, Malvern, PA, USA) and Humira (Abbott Laboratories, Abbott Park, IL, USA) are biologics that have been approved by the Food and Drug Administration as therapeutics against immune-mediated diseases, such as IBD (29). The discovery of a small molecule with an oral route of administration that decreases these two inflammatory mediators expression through the selective and novel LANCL2 pathway holds similar promise in the treatment of autoimmune disorders and pathogen-initiated immunopathologies. At the cellular level, oral NSC61610 treatment significantly decreased the numbers of infiltrating neutrophils in the lungs of influenza virus-infected mice. Pulmonary neutrophil infiltration is a prominent feature of the early inflammatory response to influenza virus infection of humans, ferrets, and mice (30). Neutrophils constitute a large proportion of the inflammatory leukocytes infiltrating the lung during influenza virus infection. Although their role in influenza virus clearance is not yet well defined, it has been suggested that excessive neutrophils and neutrophil extracellular traps contribute to acute lung injury of influenza pneumonitis (31).

While differences in inflammatory markers exist throughout the course of infection, the efficacy of oral treatment with NSC61610 is most apparent during the recovery phase, in which the increased activation of immunoregulatory pathways is most prevalent. Similar improvements in the recovery phase were reported by oral treatment of influenza virus-infected mice with ABA, the first LANCL2 ligand discovered (14). Notably, the administration of ABA has been shown to activate PPAR $\gamma$ in a LANCL2-dependent manner suggesting that LANCL2 agonists 


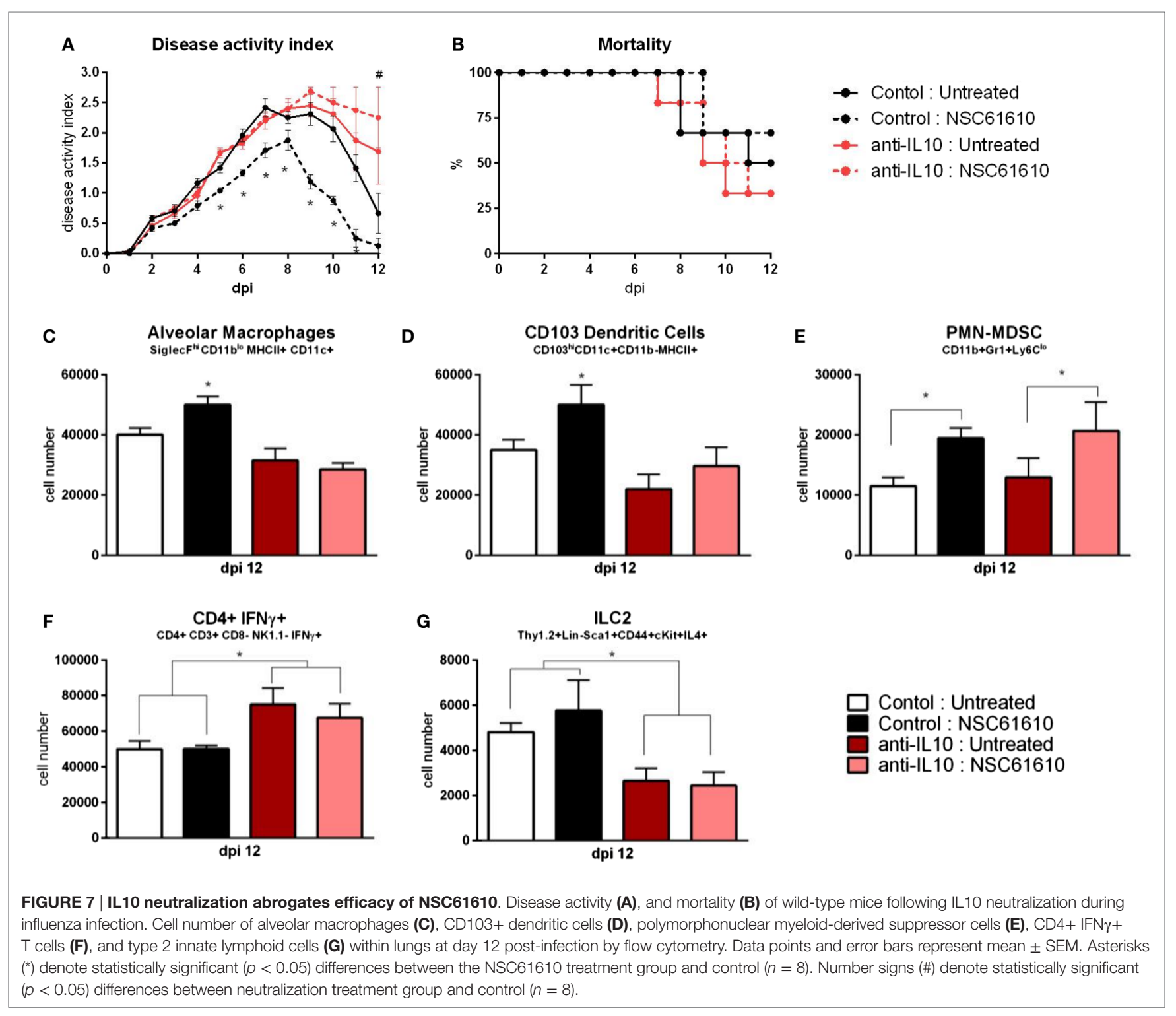

may contribute to the activation of this regulatory pathway (11). We provide molecular evidence in vivo that NSC61610 functions in a LANCL2-dependent manner during the recovery phase of infection, since the beneficial effects of NSC61610 treatment observed in wild-type mice are abrogated in LANCL2 knockout mice. Indeed, the largest differences in clinical disease measures, such as weight loss and mortality occur after the peak of infection as the NSC61610-treated wild-type group experienced an earlier and more pronounced weight gain and decrease in mortality during this phase. Oral treatment with NSC61610 triggers a shift toward a regulatory tissue environment, evidenced by the increased LANCL2-dependent expression of IL-10 in the lungs.

As a crucial regulatory cytokine, IL-10 has previously been shown to suppress pulmonary inflammation and tissue damage $(32,33)$. The cytokine exerts its regulatory control through a signaling cascade resulting in the downregulation of inflammatory cytokines, such as MCP-1 or IFN- $\gamma$, the rampant production of which contribute to the damaging cytokine storm (34). At the cellular level, oral treatment with NSC61610 induced increased levels of IL-10-producing CD8+ T cells and CD11b+ F4/80hiCX3CR1+ macrophages in the lungs. CX3CR1+ macrophages are a myeloid cell type prominent in the promotion of a homeostatic tissue environment, predominately tied to the control of intestinal immune responses to bacteria (35). Some inflammatory subsets of macrophages have been identified as susceptible to influenza infection and are crucial mediators of the well-categorized cytokine storm associated with the influenza virus (36). The ability of LANCL2 activation to promote a regulatory, IL-10-producing, macrophage population suggests efficacy of this pathway to control the damaging effects of the influenza virus in the lungs throughout the course of infection. $\mathrm{CD} 8+\mathrm{T}$ cell responses mediate resistance against intracellular infections through effector mechanisms with the potential to defend against infection (37). For example, CD8+ T cells could 

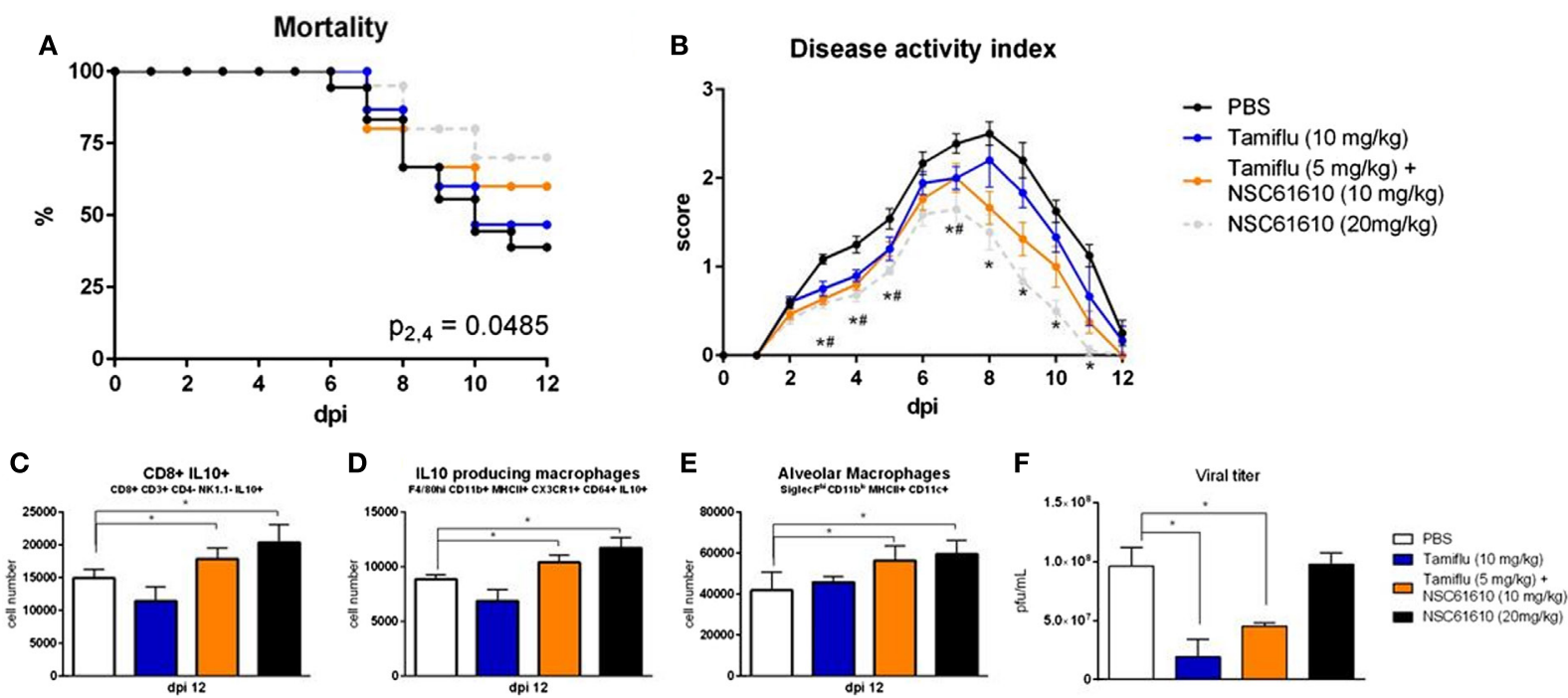

FIGURE 8 | Combination of NSC61610 and Tamiflu promotes regulatory responses and suppresses viral replication. Mortality (A) and disease activity (B) of mice treated with PBS, Tamiflu (10 mg/kg/day), Tamiflu and NSC61610 (5 and $10 \mathrm{mg} / \mathrm{kg} /$ day respectively), or NSC61610 alone (20 mg/kg/day). Cell number of CD8+ IL10+ T cells (C), IL10-producing macrophages (D), and alveolar macrophages (E) at day 12 post-infection by flow cytometry. Viral titer (F) within the lungs on day 3 post-infection by MDCK cell plaque assay. Data points and error bars represent mean \pm SEM. Asterisks $\left(^{*}\right)$ denote statistically significant $(p<0.05)$ differences between the combination treatment group and control $(n=12)$. Number signs (\#) denote statistically significant $(p<0.05)$ differences between Tamiflu treated and control groups $(n=12)$. Ampersands $(\&)$ denote statistically significant $(p<0.05)$ differences between combination and single treatment groups $(n=12)$.

eliminate influenza-virus-infected targets via the perforin/granzyme B, Fas/FasL, or TRAIL pathways (38). Meanwhile, CD8+ $\mathrm{T}$ cells have previously been identified as the main producer of IL-10 in the lungs during influenza infection (33). While recent evidence suggests that the production of IL-10 from T cells may be crucial in switching from innate to adaptive immunity during infection and lesser production may be connected to enhanced morbidity in young populations (39). Treatment with NSC61610 or similar LANCL2 ligands may help to boost this switch and prevent age-associated morbidities. The production of IL-10 from this subset, which can also be driven to secrete the effector cytokine IFN $\gamma$, is initiated in part through the presence of IL-4 within the environment (40).

IL-4 is a prototypical Th2-associated cytokine that is also produced by dendritic cells and innate lymphoid cells $(41,42)$. In particular, the loss of the type 2 innate lymphoid cell population during influenza infection creates a loss of epithelial integrity and decreased lung function (43). The increased expression of multiple ILC2-related genes upon treatment with NSC61610 indicates the involvement of LANCL2 in the generation and maintenance of this cellular phenotype. The dual roles of IL-4, as a chemoattractant stimulant of macrophages and eosinophils and an inhibitor of pro-inflammatory cytokines, such as TNF- $\alpha$ and MIP-1, may suggest that its acute elevation can allow for ample recruitment of antiviral cells while decreasing the likelihood of an excessive cytokine storm $(44,45)$. In addition to the IL-10-related effects, a key mediator of the regulatory response is the growth factor, amphiregulin. A direct product of immune cells, amphiregulin has both traditional growth factor effects, in the maintenance and stimulation of epithelial cell growth, as well as additional regulatory mechanisms, via the promotion of regulatory $\mathrm{T}$ cells $(46,47)$. The increased expression of amphiregulin with LANCL2 activation may be a key component in the reduction of epithelial necrosis and lung damage during infection.

PMN-MDSCs, alternatively referred to as granulocytic MDSC, have been shown to resolve inflammation through the attenuation of $\mathrm{T}$ cell expansion and inflammatory cytokine production via direct cell-to-cell contact, producing a highly local and specific suppressive effect (48). The presence of PMN-MDSCs during the neutralization of IL-10 suggests that this cellular phenotype is capable of being established by NSC61610 in the absence of IL-10. Without the amplification of immunoregulatory effects by IL-10, the expanded MDSC population is unable to reduce disease severity or aid in the resolution of infection. This suggests that, while MDSCs may assist in the resolution of infection, IL-10producing cells are the critical effectors of NSC61610 treatment and LANCL2 activation.

The spectrum of regulatory effects promoted by LANCL2 is dependent on signaling within myeloid cells and T cells. The promotion of IL-10-producing macrophages and CD8+ T cells is lost both in T cell and myeloid-specific knockouts of LANCL2 suggesting that interplay between the cell types is necessary to induce these effects. In contrast, the suppression of inflammatory cytokine production and increased number of alveolar macrophages remained intact within $\mathrm{T}$ cell knockouts of LANCL2. Alveolar macrophages are responsible for initiating many of the virus clearing responses in addition to the promotion of tissue remodeling and prevention of secondary infections (49-51). Therefore, the myeloid LANCL2- and IL10-dependent effects of 
NSC61610 administration are greatly beneficial to the alveolar macrophage-mediated pathways of host defense.

A concern with immunoregulatory treatment of infectious disease is impaired clearance or increased burden of the infectious agent. However, no difference in viral load was observed at day 3 post-infection with NSC61610 treatment. When also treated with Tamiflu, the viral load at day 3 post-infection was decreased. Despite a lower viral load, mice treated only with Tamiflu did not exhibit the regulatory responses exhibited by NSC61610-treated mice, suggesting the regulatory benefits of NSC61610 are independent of changes in viral load. Indeed, the therapeutic efficacy of NSC61610 has been shown in noninfectious disease models (15). Additionally, treatment with NSC61610 significantly increased survival rates compared to Tamiflu-treated mice. While Tamiflu is directly effective against specific strains of influenza $\mathrm{A}$, there is risk for adaptive strains to evade its inhibitory effects. Also, the treatment schedule of Tamiflu is very dependent on fast identification and treatment initiation with as little as a $24 \mathrm{~h}$ delay nullifying the beneficial effects. In contrast, NSC61610 treatment was initiated at 24 postinfection in all studies and retained effects.

Though not analyzed presently, the immunoregulatory benefits of LANCL2 activation during resolution of influenza virus infection may help to bolster lasting memory responses to the viral antigen. Across viral, bacterial, and parasitic infections, the increased production of IL-10 has been shown to aid in the maturation of memory CD4+ and CD8+ T cells (52-54). As a result, treatment with NSC61610, or similar LANCL2 ligand, could also aid in the efficient generation of highly specific response upon secondary exposure. However, conflicting reports exist on the effect of IL10+ CD8+ T cells, MDSCs, and immunoregulatory therapies on the ability to expand immediate memory responses $(55,56)$. Therefore, further research should be conducted into the effect of NSC61610 and LANCL2 activation on the generation and maturation of memory responses.

\section{REFERENCES}

1. Rothberg MB, Haessler SD, Brown RB. Complications of viral influenza. Am J Med (2008) 121(4):258-64. doi:10.1016/j.amjmed.2007.10.040

2. Dawood FS, Iuliano AD, Reed C, Meltzer MI, Shay DK, Cheng PY, et al. Estimated global mortality associated with the first 12 months of 2009 pandemic influenza A H1N1 virus circulation: a modelling study. Lancet Infect Dis (2012) 12(9):687-95. doi:10.1016/S1473-3099(12)70121-4

3. Kotalik J. Preparing for an influenza pandemic: ethical issues. Bioethics (2005) 19(4):422-31. doi:10.1111/j.1467-8519.2005.00453.x

4. Bassaganya-Riera J, Song R, Roberts PC, Hontecillas R. PPAR-gamma activation as an anti-inflammatory therapy for respiratory virus infections. Viral Immunol (2010) 23(4):343-52. doi:10.1089/vim.2010.0016

5. Quigley E. Influenza therapies: vaccines and antiviral drugs. Drug Discov Today (2006) 11(11-12):478-80. doi:10.1016/j.drudis.2006.04.010

6. Hackett CJ. Innate immune activation as a broad-spectrum biodefense strategy: prospects and research challenges. J Allergy Clin Immunol (2003) 112(4):686-94. doi:10.1016/S0091

7. de Jong MD, Simmons CP, Thanh TT, Hien VM, Smith GJ, Chau TN, et al. Fatal outcome of human influenza A (H5N1) is associated with high viral load and hypercytokinemia. Nat Med (2006) 12(10): 1203-7. doi:10.1038/nm1477
In summary, our data demonstrates for the first time that oral NSC61610 treatment ameliorates the morbidity and mortality associated with pandemic H1N1pdm influenza virus infection by suppressing the trafficking of inflammatory tissue-damaging cells (i.e., monocytes and neutrophils) and increasing IL-10producing CD8+ T cells and regulatory macrophages in the lungs in a LANCL2-dependent manner, thereby validating the role of the LANCL2 pathway as a novel host-targeted therapeutic against influenza that modulates the balance of effector and regulatory host responses in the lungs and systemically. NSC61610 improves clinical measures of disease compared to a current standard of care, oseltamivir (Tamiflu). Given the risk of developing resistance to Tamiflu and other agents targeting directly the virus, future studies should explore utilizing LANCL2-based hosttargeted therapeutics in combination with lower doses of licensed antiviral drugs.

\section{AUTHOR CONTRIBUTIONS}

$\mathrm{RH}$ and JB-R conceived and coordinated the study. AL, NT-J, $\mathrm{VZ}-\mathrm{R}, \mathrm{VG}$, and PL performed and analyzed the experiments described by Figures 1-8. AL, JB-R, and RH designed experiments and wrote the manuscript. SK helped in the interpretation of the SPR analyses. All authors reviewed the results and approved the final version of the manuscript.

\section{ACKNOWLEDGMENTS}

This work was supported by funds from the Nutritional Immunology and Molecular Medicine Laboratory. A LANCL2pGEX-6-P1 vector was used to express GST-LANCL2 protein, kindly provided by Dr. Laura Sturla from University of Genoa, Italy. The authors would also thank Dr. Aykut Uren of Georgetown University Medical Center for surface plasmon resonance experiments.

8. Butler D. Cheaper approaches to flu divide researchers. Nature (2007) 448(7157):976-7. doi:10.1038/448976b

9. Fedson DS. Confronting the next influenza pandemic with antiinflammatory and immunomodulatory agents: why they are needed and how they might work. Influenza Other Respi Viruses (2009) 3(4):129-42. doi:10.1111/j.1750-2659.2009.00090.x

10. Fedson DS. Confronting an influenza pandemic with inexpensive generic agents: can it be done? Lancet Infect Dis (2008) 8(9):571-6. doi:10.1016/ S1473-3099(08)70070-7

11. Bassaganya-Riera J, Guri AJ, Lu P, Climent M, Carbo A, Sobral BW, et al. Abscisic acid regulates inflammation via ligand-binding domain-independent activation of peroxisome proliferator-activated receptor gamma. J Biol Chem (2011) 286(4):2504-16. doi:10.1074/jbc.M110.160077

12. Lu P, Bevan DR, Lewis SN, Hontecillas R, Bassaganya-Riera J. Molecular modeling of lanthionine synthetase component C-like 2: a potential target for the discovery of novel type 2 diabetes prophylactics and therapeutics. $J \mathrm{Mol}$ Model (2011) 17(3):543-53. doi:10.1007/s00894-010-0748-y

13. Sturla L, Fresia C, Guida L, Grozio A, Vigliarolo T, Mannino E, et al. Binding of abscisic acid to human LANCL2. Biochem Biophys Res Commun (2011) 415(2):390-5. doi:10.1016/j.bbrc.2011.10.079

14. Hontecillas R, Roberts PC, Carbo A, Vives C, Horne WT, Genis S, et al. Dietary abscisic acid ameliorates influenza virus-associated 
disease and pulmonary immunopathology through a PPAR g-dependent mechanism. JNutr Biochem (2013) 24(6):1019-27. doi:10.1016/ j.jnutbio.2012.07.010

15. Lu P, Hontecillas R, Philipson CW, Bassaganya-Riera J. Lanthionine synthetase component C-like protein 2: a new drug target for inflammatory diseases and diabetes. Curr Drug Targets (2014) 15(6):565-72. doi:10.2174/13894501 15666140313123714

16. Chung CH, Kurien BT, Mehta P, Mhatre M, Mou S, Pye QN, et al. Identification of lanthionine synthase C-like protein- 1 as a prominent glutathione binding protein expressed in the mammalian central nervous system. Biochemistry (2007) 46(11):3262-9. doi:10.1021/bi061888s

17. Zhang W, Wang L, Liu Y, Xu J, Zhu G, Cang H, et al. Structure of human lanthionine synthetase C-like protein 1 and its interaction with Eps8 and glutathione. Genes Dev (2009) 23(12):1387-92. doi:10.1101/gad.1789209

18. Lu P, Bevan DR, Lewis SN, Hontecillas R, Bassaganya-Riera J. Molecular modeling of lanthionine synthetase component C-like protein 2: a potential target for the discovery of novel type 2 diabetes prophylactics and therapeutics. J Mol Model (2011) 17(3):543-53. doi:10.1007/s00894-010-0748-y

19. Lu P, Hontecillas R, Horne WT, Carbo A, Viladomiu M, Pedragosa M, et al. Computational modeling-based discovery of novel classes of antiinflammatory drugs that target lanthionine synthetase C-like protein 2. PLoS One (2012) 7(4):e34643. doi:10.1371/journal.pone.0034643

20. BisselP,BoesK,HinckleyJ, Jortner B, Magnin-BisselG, WerreS, etal.Exploratory studies on safety of BT-11: a proposed orally active therapeutic for Crohn's disease. Int J Toxicol (2016) 35(5):521-9. doi:10.1177/1091581816646356

21. Carbo A, Hontecillas R, Cooper J, Gandour R, Ehrich M, Bassaganya-Riera J. Lanthionine synthetase C-like receptor 2 (LANCL2): a novel therapeutic target for inflammatory bowel disease. Gastroenterology (2015) 148(4):S686-7. doi:10.1016/S0016-5085(15)32321-0

22. Enrich M, Boes K, Honckley J, Jortner B, Magnin-Bissel G, Werre S, et al. Safety profile of BT-11: a novel LANCL2-based therapeutic for Crohn's disease. Society of Toxicology 2015 Meeting. San Diego (2015).

23. Carbo A, Gandour RD, Hontecillas R, Philipson N, Uren A, BassaganyaRiera J. An N,N-Bis(benzimidazolylpicolinoyl)piperazine (BT-11): a novel lanthionine synthetase C-like 2-based therapeutic for inflammatory bowel disease. JMed Chem (2016) 59(22):10113-26. doi:10.1021/acs. jmedchem.6b00412

24. Bassaganya-Riera J, Reynolds K, Martino-Catt S, Cui Y, Hennighausen L, Gonzalez F, et al. Activation of PPAR gamma and delta by conjugated linoleic acid mediates protection from experimental inflammatory bowel disease. Gastroenterology (2004) 127(3):777-91. doi:10.1053/j.gastro.2004.06.049

25. Guri AJ, Hontecillas R, Bassaganya-Riera J. Abscisic acid synergizes with rosiglitazone to improve glucose tolerance and down-modulate macrophage accumulation in adipose tissue: possible action of the cAMP/ PKA/PPAR gamma axis. Clin Nutr (2010) 29(5):646-53. doi:10.1016/j. clnu.2010.02.003

26. Guri AJ, Evans NP, Hontecillas R, Bassaganya-Riera J. T cell PPAR gamma is required for the anti-inflammatory efficacy of abscisic acid against experimental inflammatory bowel disease. J Nutr Biochem (2011) 22(9):812-9. doi:10.1016/j.jnutbio.2010.06.011

27. Fresia C, Vigliarolo T, Guida L, Booz V, Bruzzone S, Sturla L, et al. G-protein coupling and nuclear translocation of the human abscisic acid receptor LANCL2. Sci Rep (2016) 6:26658. doi:10.1038/srep26658

28. Veckman V, Osterlund P, Fagerlund R, Melén K, Matikainen S, Julkunen I. TNF-alpha and IFN-alpha enhance influenza-A-virus-induced chemokine gene expression in human A549 lung epithelial cells. Virology (2006) 345(1):96-104. doi:10.1016/j.virol.2005.09.043

29. van Heel DA, Udalova IA, De Silva AP, McGovern DP, Kinouchi Y, Hull J, et al. Inflammatory bowel disease is associated with a TNF polymorphism that affects an interaction between the OCT1 and NF(-kappa)B transcription factors. Hum Mol Genet (2002) 11(11):1281-9. doi:10.1093/hmg/ 11.11 .1281

30. Tate MD, Deng YM, Jones JE, Anderson GP, Brooks AG, Reading PC. Neutrophils ameliorate lung injury and the development of severe disease during influenza infection. J Immunol (2009) 183(11):7441-50. doi:10.4049/ jimmunol.0902497
31. Narasaraju T, Yang E, Samy RP, Ng HH, Poh WP, Liew AA, et al. Excessive neutrophils and neutrophil extracellular traps contribute to acute lung injury of influenza pneumonitis. Am J Pathol (2011) 179(1):199-210. doi:10.1016/ j.ajpath.2011.03.013

32. Cox G. IL-10 enhances resolution of pulmonary inflammation in vivo by promoting apoptosis of neutrophils. Am J Physiol (1996) 271(4 Pt 1):L566-71.

33. Sun J, Madan R, Karp CL, Braciale TJ. Effector T cells control lung inflammation during acute influenza virus infection by producing IL-10. Nat Med (2009) 15(3):277-84. doi:10.1038/nm.1929

34. Ouyang W, Rutz S, Crellin NK, Valdez PA, Hymowitz SG. Regulation and functions of the IL-10 family of cytokines in inflammation and disease. Annu Rev Immunol (2011) 29:71-109. doi:10.1146/annurev-immunol-031210-101312

35. Longman RS, Diehl GE, Victorio DA, Huh JR, Galan C, Miraldi ER, et al. $\mathrm{CX}(3) \mathrm{CR} 1(+)$ mononuclear phagocytes support colitis-associated innate lymphoid cell production of IL-22. J Exp Med (2014) 211(8):1571-83. doi:10.1084/jem.20140678

36. Hofmann P, Sprenger H, Kaufmann A, Bender A, Hasse C, Nain M, et al. Susceptibility of mononuclear phagocytes to influenza A virus infection and possible role in the antiviral response. J Leukoc Biol (1997) 61(4):408-14.

37. Harty JT, Tvinnereim AR, White DW. CD8+ T cell effector mechanisms in resistance to infection. Annu Rev Immunol (2000) 18:275-308. doi:10.1146/ annurev.immunol.18.1.275

38. Sanders CJ, Doherty PC, Thomas PG. Respiratory epithelial cells in innate immunity to influenza virus infection. Cell Tissue Res (2011) 343(1):13-21. doi:10.1007/s00441-010-1043-z

39. Verhoeven D, Perry S. Differential mucosal IL-10-induced immunoregulation of innate immune responses occurs in influenza infected infants/toddlers and adults. Immunol Cell Biol (2016). doi:10.1038/icb.2016.91

40. Zhao Y, Zhao H, Sun Y, Hao J, Qi X, Zhou X, et al. IL-4 induces a suppressive IL-10-producing CD8+ T cell population via a Cdkn2a-dependent mechanism. J Leukoc Biol (2013) 94(6):1103-12. doi:10.1189/jlb.0213064

41. Licona-Limón P, Kim LK, Palm NW, Flavell RA. TH2, allergy and group 2 innate lymphoid cells. Nat Immunol (2013) 14(6):536-42. doi:10.1038/ni.2617

42. Maroof A, Penny M, Kingston R, Murray C, Islam S, Bedford PA, et al. Interleukin-4 can induce interleukin-4 production in dendritic cells. Immunology (2006) 117(2):271-9. doi:10.1111/j.1365-2567.2005.02305.x

43. Monticelli LA, Sonnenberg GF, Abt MC, Alenghat T, Ziegler CG, Doering TA, et al. Innate lymphoid cells promote lung-tissue homeostasis after infection with influenza virus. Nat Immunol (2011) 12(11):1045-54. doi:10.1031/ ni.2131

44. Jain-Vora S, Wert SE, Temann UA, Rankin JA, Whitsett JA. Interleukin-4 alters epithelial cell differentiation and surfactant homeostasis in the postnatal mouse lung. Am J Respir Cell Mol Biol (1997) 17(5):541-51.

45. Levings MK, Schrader JW. IL-4 inhibits the production of TNF-alpha and IL-12 by STAT6-dependent and -independent mechanisms. J Immunol (1999) 162(9):5224-9.

46. Jamieson AM, Pasman L, Yu S, Gamradt P, Homer RJ, Decker T, et al. Role of tissue protection in lethal respiratory viral-bacterial coinfection. Science (2013) 340(6137):1230-4. doi:10.1126/science.1233632

47. Zaiss DM, van Loosdregt J, Gorlani A, Bekker CP, Gröne A, Sibilia M, et al. Amphiregulin enhances regulatory $\mathrm{T}$ cell-suppressive function via the epidermal growth factor receptor. Immunity (2013) 38(2):275-84. doi:10.1016/ j.immuni.2012.09.023

48. Ost M, Singh A, Peschel A, Mehling R, Rieber N, Hartl D. Myeloid-derived suppressor cells in bacterial infections. Front Cell Infect Microbiol (2016) 6:37. doi:10.3389/fcimb. 2016.00037

49. Ghoneim HE, Thomas PG, McCullers JA. Depletion of alveolar macrophages during influenza infection facilitates bacterial superinfections. J Immunol (2013) 191(3):1250-9. doi:10.4049/jimmunol.1300014

50. Kim HM, Lee YW, Lee KJ, Kim HS, Cho SW, van Rooijen N, et al. Alveolar macrophages are indispensable for controlling influenza viruses in lungs of pigs. J Virol (2008) 82(9):4265-74. doi:10.1128/JVI.02602-07

51. Schneider C, Nobs SP, Heer AK, Kurrer M, Klinke G, van Rooijen N, et al. Alveolar macrophages are essential for protection from respiratory failure and associated morbidity following influenza virus infection. PLoS Pathog (2014) 10(4):e1004053. doi:10.1371/journal.ppat.1004053 
52. Foulds KE, Rotte MJ, Seder RA. IL-10 is required for optimal CD8 T cell memory following Listeria monocytogenes infection. JImmunol (2006) 177(4):2565-74. doi:10.4049/jimmunol.177.4.2565

53. Laidlaw BJ, Cui W, Amezquita RA, Gray SM, Guan T, Lu Y, et al. Production of IL-10 by CD4(+) regulatory T cells during the resolution of infection promotes the maturation of memory CD8(+) T cells. Nat Immunol (2015) 16(8):871-9. doi:10.1038/ni.3224

54. Wipasa J, Okell L, Sakkhachomphop S, Suphavilai C, Chawansuntati $\mathrm{K}$, Liewsaree W, et al. Short-lived IFN-gamma effector responses, but long-lived IL-10 memory responses, to malaria in an area of low malaria endemicity. PLoS Pathog (2011) 7(2):e1001281. doi:10.1371/journal.ppat. 1001281

55. Raber PL, Sierra RA, Thevenot PT, Shuzhong Z, Wyczechowska DD, Kumai $\mathrm{T}$, et al. T cells conditioned with MDSC show an increased anti-tumor activity after adoptive T cell based immunotherapy. Oncotarget (2016) 7(14):17565-78. doi:10.18632/oncotarget.8197
56. Sawant A, Schafer CC, Ponnazhagan S, Deshane JS. The dual targeting of immunosuppressive cells and oxidants promotes effector and memory T-cell functions against lung cancer. Oncoimmunology (2014) 3(1):e27401. doi:10.4161/onci.27401

Conflict of Interest Statement: The authors declare that the research was conducted in the absence of any commercial or financial relationships that could be construed as a potential conflict of interest.

Copyright (c) 2017 Leber, Bassaganya-Riera, Tubau-Juni, Zoccoli-Rodriguez, Lu, Godfrey, Kale and Hontecillas. This is an open-access article distributed under the terms of the Creative Commons Attribution License (CC BY). The use, distribution or reproduction in other forums is permitted, provided the original author(s) or licensor are credited and that the original publication in this journal is cited, in accordance with accepted academic practice. No use, distribution or reproduction is permitted which does not comply with these terms. 